\title{
Ambient air quality trends and driving factor analysis in Beijing, 1983-2007
}

\author{
Ju Zhang, Zhiyun Ouyang*, Hong Miao, Xiaoke Wang \\ State Key Laboratory of Urban and Regional Ecology, Research Center for Eco-Environmental Sciences, Chinese Academy of Sciences, \\ Beijing 100085, China.E-mail: zhang_ju@mails.gucas.ac.cn
}

Received 30 April 2010; revised 26 May 2010; accepted 03 June 2010

\begin{abstract}
The rapid development in Beijing, the capital of China, has resulted in serious air pollution problems. Meanwhile great efforts have been made to improve the air quality, especially since 1998. The variation in air quality under the interaction of pollution and control in this mega city has attracted much attention. We analyzed the changes in ambient air quality in Beijing since the 1980's using the Daniel trend test based on data from long-term monitoring stations. The results showed that different pollutants displayed three trends: a decreasing trend, an increasing trend and a flat trend. $\mathrm{SO}_{2}$, dustfall, $\mathrm{B}[\mathrm{a}] \mathrm{P}, \mathrm{NO}_{2}$ and $\mathrm{PM}_{10}$ fit decreasing trend pattern, while $\mathrm{NO} x$ showed an increasing trend, and CO, ozone pollution, total suspended particulate (TSP), as well as Pb fit the flat trend. The cause of the general air pollution in Beijing has changed from being predominantly related to coal burning to mixed traffic exhaust and coal burning related pollution. Seasonally, the pollution level is typically higher during the heating season from November to the following March. The interaction between pollution sources change and implementation of air pollution control measures was the main driving factor that caused the variation in air quality. Changes of industrial structure and improved energy efficiency, the use of clean energy and preferred use of clean coal, reduction in pollution sources, and implementation of advanced environmental standards have all contributed to the reduction in air pollution, particularly since 1998 .
\end{abstract}

Key words: ambient air quality; trend analysis; driving factor; particulate matter

DOI: $10.1016 /$ S1001-0742(10)60667-5

Citation: Zhang J, Ouyang Z Y, Miao H, Wang X K, 2011. Ambient air quality trends and driving factor analysis in Beijing, $1983-2007$. Journal of Environmental Sciences, 23(12): 2019-2028

\section{Introduction}

Major cities in the world are facing increasingly serious urban air pollution problems which are reducing the quality of life for residents (Fenger, 2009; www.unep.org/urban_environment/Issues/urban_air.asp). A lot of attention has been given to urban ambient air quality, especially to the negative effects of urban air pollution on human health, climate change, visibility, etc. (Hyslop, 2009; Wang et al., 2008a). The air quality trend is the basic concern. Recent research has indicated that worldwide trends in ambient air quality typically show reductions in the concentration of some pollutants, such as $\mathrm{SO}_{2}$ and $\mathrm{NO}_{2}$. However, the air pollution in major cities, especially in developing countries, is still poor and can become even more serious as those cities undergo development (Gupta and Kumar, 2006; Lin et al., 2001).

Air pollution is the result of complex interactions caused by both natural processes and human activities. Research has identified that meteorological conditions have strong links with pollutant levels. Meteorological variability typically accounts for $40 \%-70 \%$ of ozone variability and $20 \%-50 \%$ of particulate matter (PM) variability in the

\footnotetext{
* Corresponding author. E-mail: zyouyang@rcees.ac.cn
}

southwestern United States (Wise and Comrie, 2005). But in the city the anthropogenic impact is more significant. The increases in population, motor vehicles and energy consumption usually lead to increases in air pollutant emissions, and a reduction in air quality in cities (Mayer, 1999; Mukerjee, 2001). Kahn (1997) identified that increases in manufacturing have a statistically significant impact on particulate levels. The anthropogenic activities also have positive impact for example air pollution control measures could be helpful for better air. The worldwide downward trend in pollutant concentrations is also related to increasingly strict restrictions and measures which local governments and international organizations have imposed (Baldasano et al., 2003).

Beijing, the capital of China, is a typical megacity in developing country which has experienced rapid development in the last two decades. It is facing the dilemma between development and environmental protection as developed countries once did (Weatherley and Timmis, 2001). But different from developed countries which experienced hundreds years of history on pollution and control, the changes in Beijing are taking place in shorter time within several decades which can multiply the effect and caused may be even more complex problems. The 
rapid development of Beijing has resulted in serious air pollution problems that the air quality of Beijing was not only worse than many international cities in Europe and North America, but was also worse than many domestic cities (World Bank, 2007; Zhou et al., 2007). Meanwhile significant efforts have been made to improve the air quality in Beijing, particularly since 1998. However, there is poor understanding of the variation in air quality under the interaction between increased pollution sources and implementation of air pollution control measures in such fast developing mega city. An improved understanding of the characteristics, variability and driving factors of the air pollution in Beijing is essential for the formation of effective management strategies of urban air pollution control. In this study, data from long-term monitoring stations has been used to analyze changes in the ambient air quality in Beijing since the 1980's. Annual and seasonal variations have been discussed. The driving factors were analyzed to explain the changes in air quality in this fast developing mega city.

\section{Materials and methods}

\subsection{Study areas}

Beijing is located in the northwest of the North China Plain, at $39^{\circ} \mathrm{N}, 116^{\circ} \mathrm{E}$. It falls within the warm temperate zone and has a semi-humid climate. The annual average temperature is $10-12^{\circ} \mathrm{C}$ and the annual average precipitation is about $644 \mathrm{~mm}$. Beijing has distinctive seasons. Spring is warm and windy, summer is hot and rainy, autumn is cool and sunny, and winter is cold and dry. Sometimes in spring, dust storms occur on the Mongolian Plateau which is to the northwest of Beijing and these may be transmitted to the city via strong winds causing dusty days.

According to the data from Beijing statistical yearbook (Beijing Municipal Statistical Bureau, 1983-2007), the city area covers $16,410 \mathrm{~km}^{2}$, including $1250 \mathrm{~km}^{2}$ of builtup area. The population has increased from 9.5 million people in 1983 to 16.3 million people in 2007. The GDP in 2007 was 935.3 billion CNY, about 51 times that the GDP in 1983, which is equal an approximate annual increase of $17.8 \%$. Compared with the rapid growth period of the US (1870-1913, 3.94\% average annual GDP growth) and Japan (1950-1973, 9.29\% average annual GDP growth), the growth in GDP in Beijing is about 3.5 times and 0.9 times higher, respectively (Maddison, 2003). Also in the past 25 years, the energy consumption has increased from 22 million tons of standard coal equivalent (SCE) in 1985 to 63 million tons per year in 2007, and the possession of private motor vehicles has increased 21 fold from 140,000 vehicles to 3,072,000 vehicles.

\subsection{Data sources and method}

Air quality data from 1983 to 2007 from long-term monitoring stations were used to analyze the changes in Beijing's air quality. Concentrations of $\mathrm{SO}_{2}$, nitrous oxides (NOx), CO, total suspended particulate (TSP), dustfall, $\mathrm{Pb}$ and benzo[a]pyrene $(\mathrm{B}[\mathrm{a}] \mathrm{P})$, and days when ozone concentration exceeded the air standard, are the main indicators discussed in this article. Since 1998, $\mathrm{NO}_{2}$ and $\mathrm{PM}_{10}$ (particulate matter $<10 \mu \mathrm{m}$ ) have gradually been substituted for NOx and TSP. The annual average concentrations of the indicators were used to analyze the annual variation of the pollutants. A year was divided into the heating and non-heating seasons. The heating season is from November to the following March, and the nonheating season is from April to October. Seasonal averages were compared. The economic and social data are from the Beijing statistical yearbook.

The Daniel trend test, which uses the Spearman correlation coefficient, was applied to analyze the trends of the air quality in Beijing and its statistical significance $(\mathrm{Qu}$, 2002). Its formula is as follows.

$r_{\mathrm{s}}=1-\left[6 \sum_{i=1}^{n}\left(x_{i}-y_{i}\right)^{2}\right] /\left(n^{3}-n\right)$

where, $r_{\mathrm{s}}$ is the correlation coefficient, $n$ is the number of years, $x_{i}$ is the ordinal number of the ascending sorted annual average of year $i$, and $y_{i}$ is the ordinal number of year $i$ counted by time order. Positive or negative values of $r_{\mathrm{s}}$ show increasing or decreasing trends respectively. The absolute value of $r_{\mathrm{s}}$ indicates the magnitude of any variation. We also used statistics to compare $r_{\mathrm{s}}$ with the critical value $W p$. If $r_{\mathrm{s}}$ is equal to or greater than $W p$, the trend has statistical significance, with $P$ being the significance level.

Trends over the past 25 years were analyzed by this method. Variations in pollutant concentrations before and after 1998 were also analyzed separately using the Daniel trend test. The Wilcoxon test was used for comparisons. A partial correlation analysis was used for the main driving factor analysis.

\section{Results}

\subsection{Annual trends of pollutants}

According to the characteristics of variations in the pollutant concentrations, the general trends in the air pollution in Beijing can be divided into two time periods. From 1983 to 1998 the concentrations of pollutants typically increased, and the air quality worsened. From 1998 to 2007 most of the pollutants showed downward trends, and the air quality improved.

From the results of the Daniel trend tests, different pollutants had different trends (Fig. 1). (1) $\mathrm{SO}_{2}$ had a generally decreasing trend over the 25 year period ( $p<0.01$, Fig. 1a). There was a fluctuating increase before 1998, from $0.085 \mathrm{mg} / \mathrm{m}^{3}$ in 1983 to $0.134 \mathrm{mg} / \mathrm{m}^{3}$ in 1991 . From 1998 the concentration of $\mathrm{SO}_{2}$ declined from 0.120 to $0.047 \mathrm{mg} / \mathrm{m}^{3}$ in 2007. The decreasing trend after 1998 was significant $(p<0.01)$. (2) NO $x$ had significant increasing trend in the past two decades, and the concentration only reduced slightly after 1998 ( $p<0.01$, Fig. 1d). Before 1998 NO $x$ concentrations had a highly significant increasing 

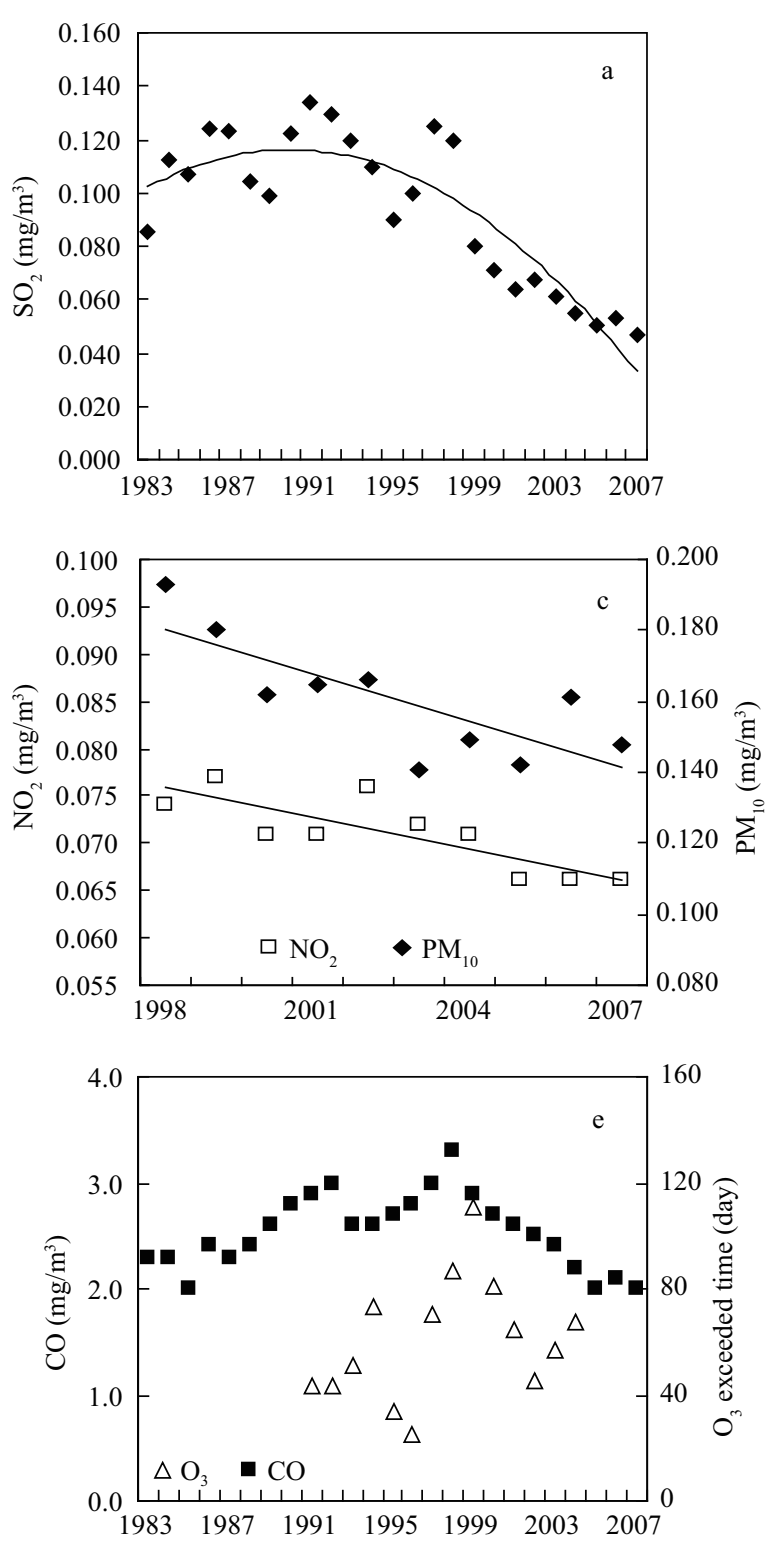
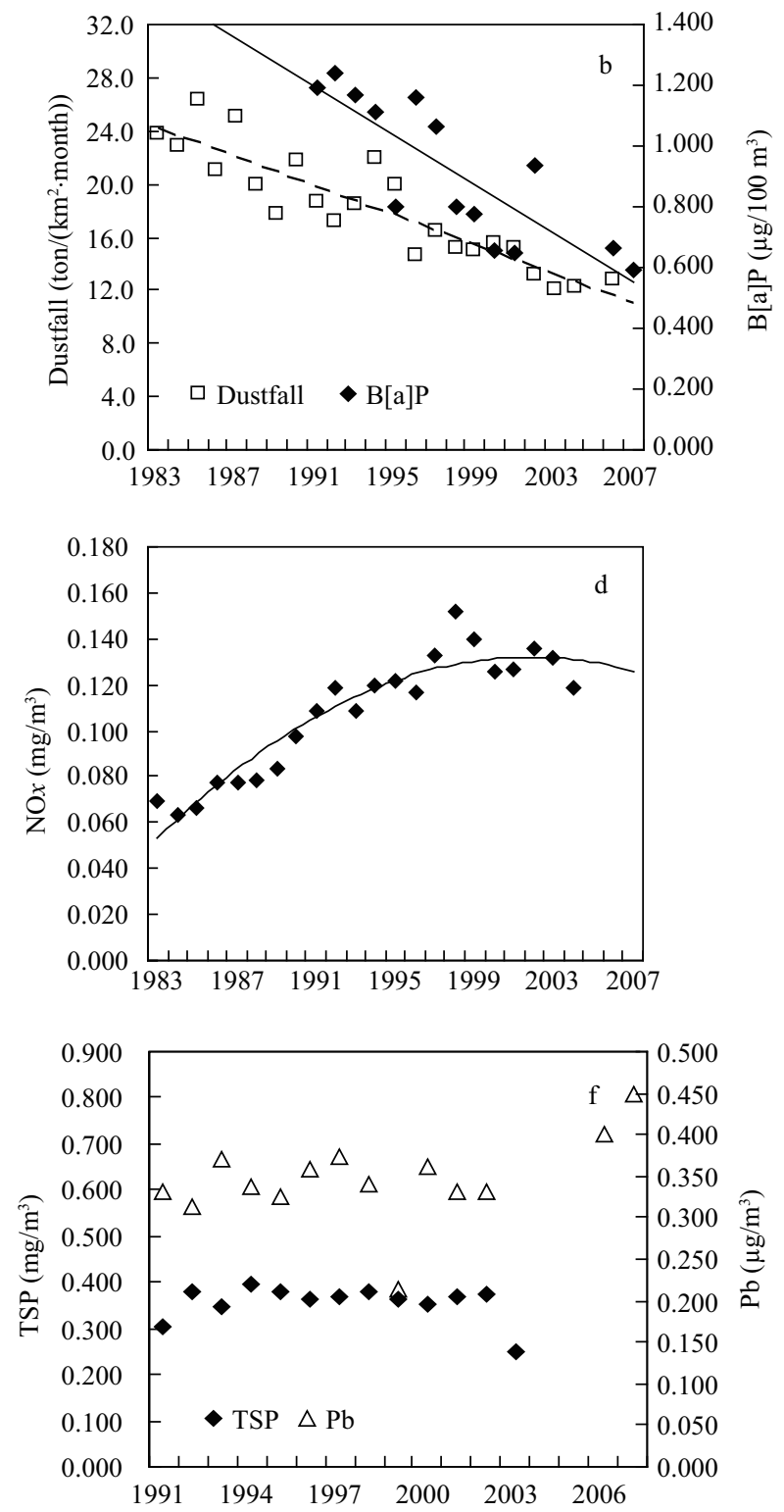

Fig. 1 Annual trends in pollutant concentrations. Three general trends: a decreasing trend (a, b, c), an increasing trend (d) and a flat trend (e, f).

trend, with concentrations rising from $0.069 \mathrm{mg} / \mathrm{m}^{3}$ in 1983 to $0.152 \mathrm{mg} / \mathrm{m}^{3}$ in $1998(p<0.01)$. After 1998 the concentration reduced a little, but this was not significant. (3) $\mathrm{CO}$ and ozone pollution got worse at first and then improved, with no significant overall trend (Fig. 1e). Before 1998, the CO concentration showed an extremely significant increasing trend, rising from $2.3 \mathrm{mg} / \mathrm{m}^{3}$ in 1983 to $3.3 \mathrm{mg} / \mathrm{m}^{3}$ in $1998(p<0.01)$. Following 1998 , the CO pollution showed a significant declining trend, reducing to $2.0 \mathrm{mg} / \mathrm{m}^{3}$ in $2007(p<0.01)$. Ozone pollution showed fluctuating changes, with no significant increase before 1998 and no significant decrease after 1998. (4) TSP and $\mathrm{Pb}$ had no significant trends (Fig. 1f). The concentration of TSP remained constant at around $0.360 \mathrm{mg} / \mathrm{m}^{3}$ and the concentration of $\mathrm{Pb}$ was constant around $0.340 \mu \mathrm{g} / \mathrm{m}^{3}$. (5) Dustfall and $\mathrm{B}[\mathrm{a}] \mathrm{P}$ showed a continuous reduction over the last two decades ( $p<0.01$, Fig. 1b). Dustfall reduced from $23.8 \mathrm{ton} /\left(\mathrm{km}^{2} \cdot \mathrm{month}\right)$ in 1983 to $12.8 \mathrm{ton} /\left(\mathrm{km}^{2} \cdot \mathrm{month}\right)$ in 2006. B[a]P reduced from $0.0119 \mu \mathrm{g} / \mathrm{m}^{3}$ in 1983 to 0.0059 $\mu \mathrm{g} / \mathrm{m}^{3}$ in 2007. Even in the period before 1998 when other pollutants had increasing trends, dustfall $(p<0.01)$ and $\mathrm{B}[\mathrm{a}] \mathrm{P}(p<0.05)$ levels declined. (6) $\mathrm{NO}_{2}$ and $\mathrm{PM}_{10}$, the substitute indicators of nitrogen oxides and particulate matter since 1998, had significant decreasing trends $(p<$ 0.01, Fig. 1c). From 1998 to $2007 \mathrm{NO}_{2}$ declined from 0.074 to $0.066 \mathrm{mg} / \mathrm{m}^{3}$ and $\mathrm{PM}_{10}$ declined from 0.193 to $0.148 \mathrm{mg} / \mathrm{m}^{3}$.

\subsection{Change of the ratio of pollutants}

The variation in pollutant concentrations also caused a change in the general characteristics of the air pollution in Beijing. In 1984, the $\mathrm{SO}_{2}$ concentration in Beijing was $0.112 \mathrm{mg} / \mathrm{m}^{3}$ while the concentration of $\mathrm{NO} x$ was $0.063 \mathrm{mg} / \mathrm{m}^{3}$. The ratio of $\mathrm{NO} x$ to $\mathrm{SO}_{2}$ was 0.56 which shows the impact of $\mathrm{SO}_{2}$ at that time. Similarly, the ratio of $\mathrm{NO}_{2}$ to $\mathrm{SO}_{2}$ was 0.62 in 1998. Over the past two decades the concentration of $\mathrm{SO}_{2}$ has declined while the concentration of NOx has increased. The ratio of NOx to $\mathrm{SO}_{2}$ rapidly increased with only minor fluctuations in some years (Fig. 2). The ratio reached 2.164 in 2004, which was 


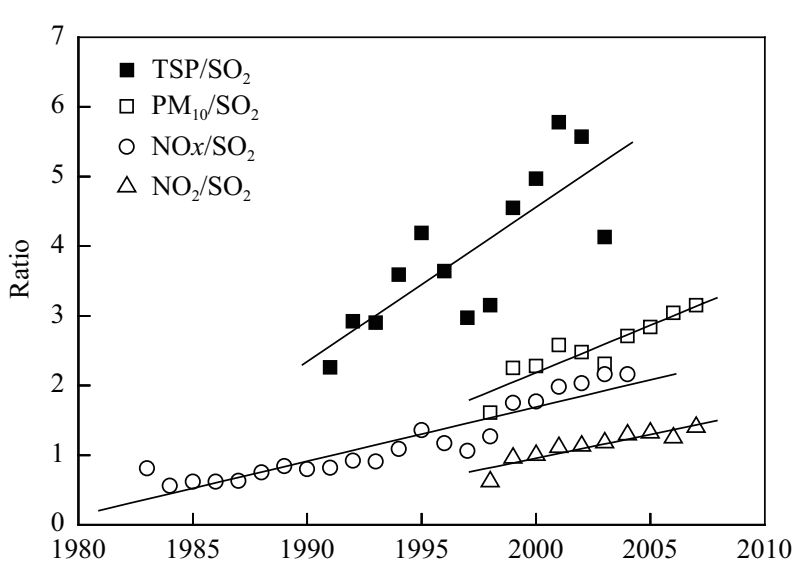

Fig. 2 Annual change in the ratio of $\mathrm{NO} x$ to $\mathrm{SO}_{2}, \mathrm{NO}_{2}$ to $\mathrm{SO}_{2}$, TSP to $\mathrm{SO}_{2}$ and $\mathrm{PM}_{10}$ to $\mathrm{SO}_{2}$.

the maximum over the study period. The concentration of $\mathrm{NO}_{2}$ has declined in the recent years, but the ratio of $\mathrm{NO}_{2}$ to $\mathrm{SO}_{2}$ continuously increased to 1.40 in 2007 . The increasing difference between $\mathrm{SO}_{2}$ and $\mathrm{NO}_{2} / \mathrm{NO} x$ shows the increasing impact of nitrogen oxide over this period. The ratio of TSP to $\mathrm{SO}_{2}$ and $\mathrm{PM}_{10}$ to $\mathrm{SO}_{2}$ were 2.26 and 1.61, respectively in 1991 and 1998, and increased to 5.78 and 3.15 , respectively in 2001 and 2007 . This reflected the increasing impact of particulate matter.

\subsection{Comparison in heating and non-heating seasons}

In the past two decades, average concentrations of $\mathrm{SO}_{2}$, $\mathrm{NO} x, \mathrm{CO}, \mathrm{TSP}, \mathrm{Pb}$ and $\mathrm{B}[\mathrm{a}] \mathrm{P}$, were significantly higher during the heating season than in non-heating season $\left(p<0.01\right.$, Fig. 3). $\mathrm{SO}_{2}$ showed the biggest difference, with the $\mathrm{SO}_{2}$ concentration during heating season about 0.215 $\mathrm{mg} / \mathrm{m}^{3}$, which is 4.7 times higher than that in the nonheating season. The difference in TSP was the smallest and the concentration during the heating season was 1.3 times that in the non-heating season.

\subsection{Driving factors analysis}

Since 1983, the economy of Beijing has developed quickly. The population grew fast, and energy consumption and the number of vehicles increased rapidly. These increases caused adverse impacts to air quality. However, a series of protective measures were implemented at the same time to reduce pollution. The interaction between

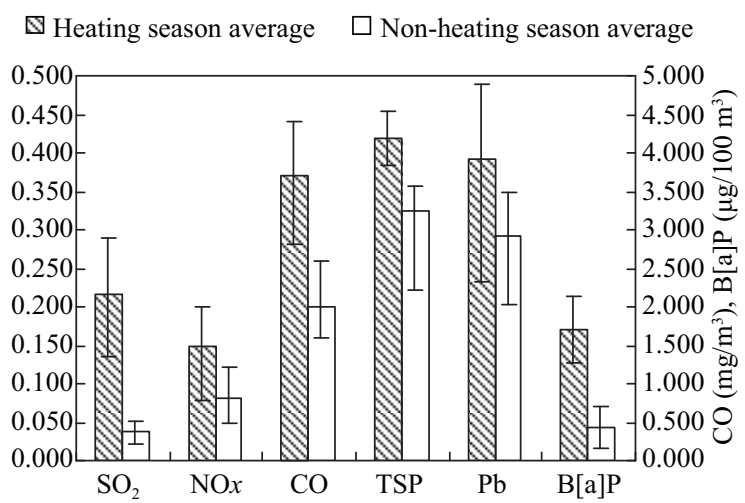

Fig. 3 Comparison of pollutant concentrations in heating and nonheating seasons in Beijing. increased pollution sources and protective measures was the main driving factor that caused the change in ambient air quality.

\subsubsection{Industrial structure}

Change of the industrial structure could have impact on air quality. The proportions of GDP contributed by primary, secondary and tertiary industries were $7: 61.5: 31.5$ in 1983, taking 100 as the whole (Fig. 4). It showed that secondary industries, which contributed a significant portion of GDP during the city's industrialization and development but also required a lot of energy and increased the emission of pollutants, is the main industry at that time. In 1983 the concentration of $\mathrm{SO}_{2}$ was $0.085 \mathrm{mg} / \mathrm{m}^{3}$. The industrial structure has been gradually adjusted that the dominant industry of Beijing has changed from secondary industries to tertiary industries. The proportions of GDP contributed by primary, secondary and tertiary industries were $1.1: 26.8: 72.1$ in 2007 . The proportion of GDP contributed by industry declined from $53.9 \%$ to $22.3 \%$. The concentration of $\mathrm{SO}_{2}$ was $0.047 \mathrm{mg} / \mathrm{m}^{3}$ in 2007 , declined by a half approximately. Similarly, the proportion of secondary industry in total energy consumption has dropped from $65.21 \%$ in 1987 to $43.12 \%$ in 2007 , although secondary industry is still the biggest consumer of energy (Fig. 5). At the same time the proportion of total energy consumption by tertiary industries has increased from $16.72 \%$ to $38.75 \%$, which is almost equal to the decline in energy consumption by secondary industry. Adjusting industrial structure was helpful in reducing energy consumption and protecting air quality. This type of replacement, a change to industries that need less energy and cause less pollution, was one of the driving factors that lead to better air quality.

\subsubsection{Energy use}

Energy use, especially energy derived from fossil fuels, may cause pollution.

The energy generation pattern could have impact on polluted sources. About $90 \%$ of $\mathrm{SO}_{2}$ and $80 \%$ of PM are resulted from coal burning by organized emissions such as in industries and power stations. Coal was the main energy source in Beijing for many years and caused serious problems as an important polluted source (Fig. 6). It is estimated that the $\mathrm{SO}_{2}$ emissions for the same quantity of heat generated by burning coal and natural gas is 119:1, and the emission of particulate matter from those fuel sources is 615:1 (Qu, 1998). The quantity of coal use in the heating season was twice that in the non-heating season and this increased the $\mathrm{SO}_{2}$ concentration 4.7 times in winter and raised the annual average. However, the situation has changed recently. Using the same standard coal equivalents (SCE), the measured proportion of coal in the total energy consumption has dropped from $60.74 \%$ in 1983 to $16.35 \%$ in 2007 , while the proportion of natural gas, which was first used in 1988, has increased from $0.43 \%$ in 1989 to $7.11 \%$ in 2007 . During this period, the concentration of $\mathrm{SO}_{2}$ dropped from $0.085 \mathrm{mg} / \mathrm{m}^{3}$ in 1983 to $0.047 \mathrm{mg} / \mathrm{m}^{3}$ in 2007 . The reduction in $\mathrm{SO}_{2}$ concen- 


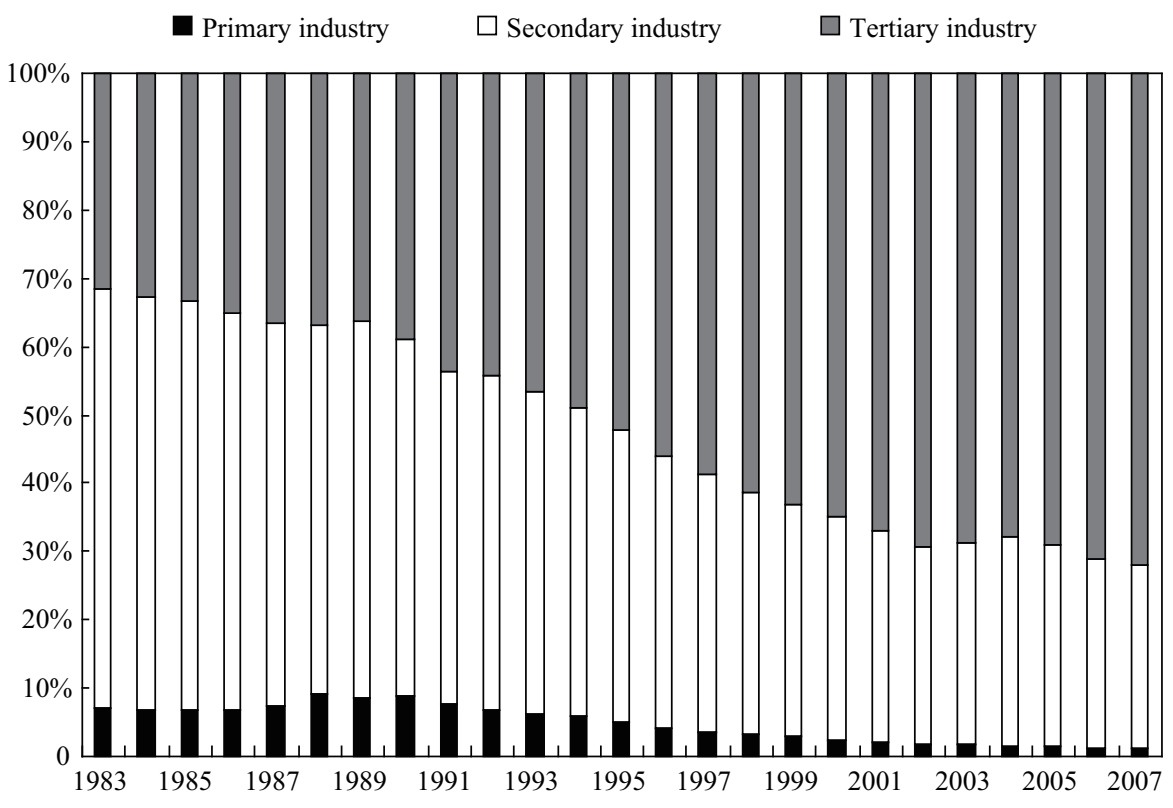

Fig. 4 Composition of gross domestic product from 1983 to 2007.

D Primary industry $\square$ Secondary industry

N Tertiary industry $\quad$ Residential consumption

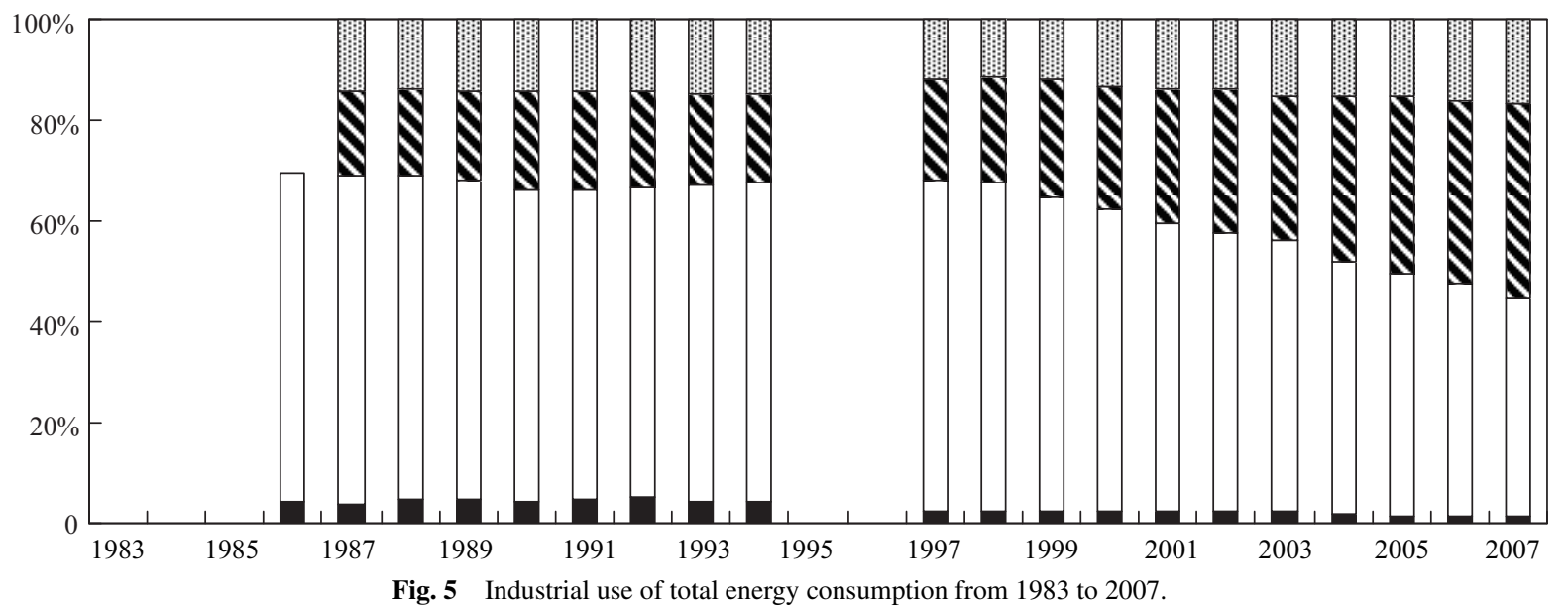

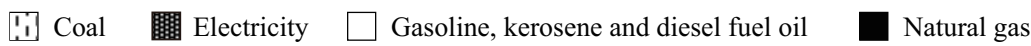

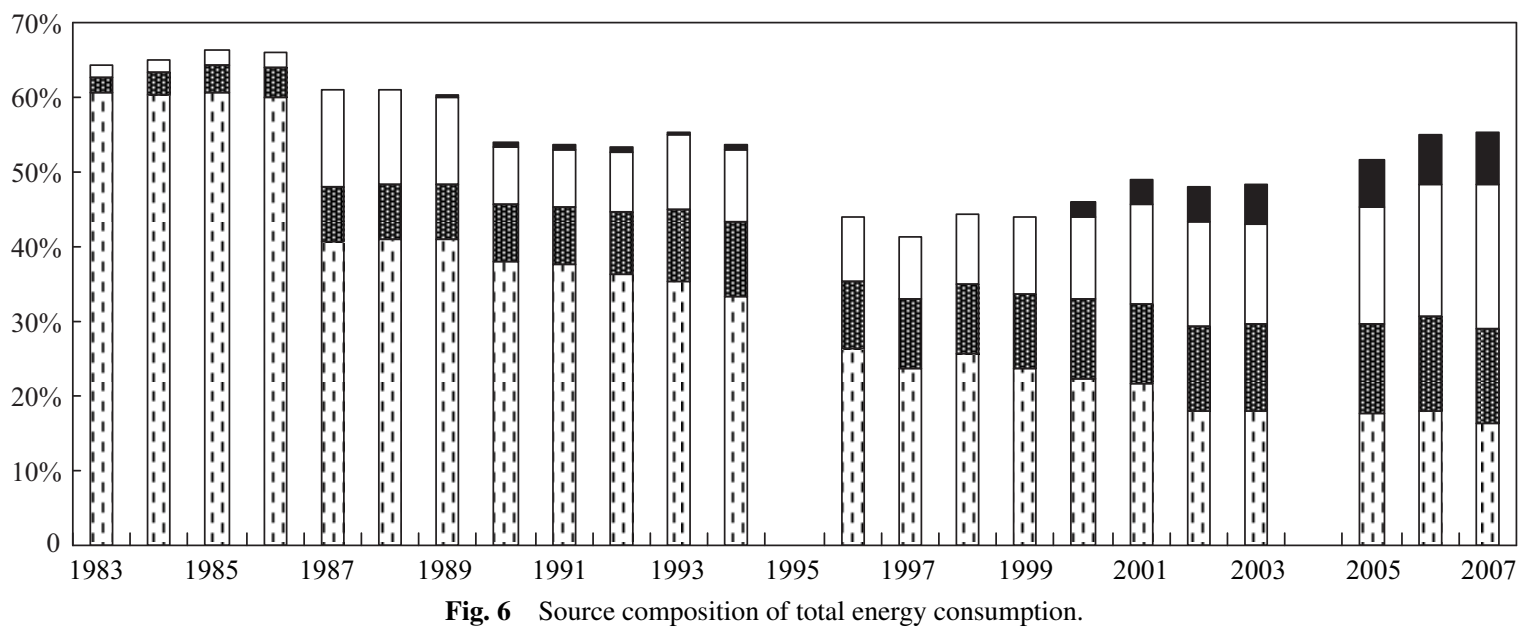

tration was significantly correlated with the increase in supply of natural gas in recent years ( $p<0.01$, Fig. 7a). It is clear that improving energy generation by using clean energy sources to replace polluted sources will improve air quality.

It is not easy facilitate a great change in the energy 

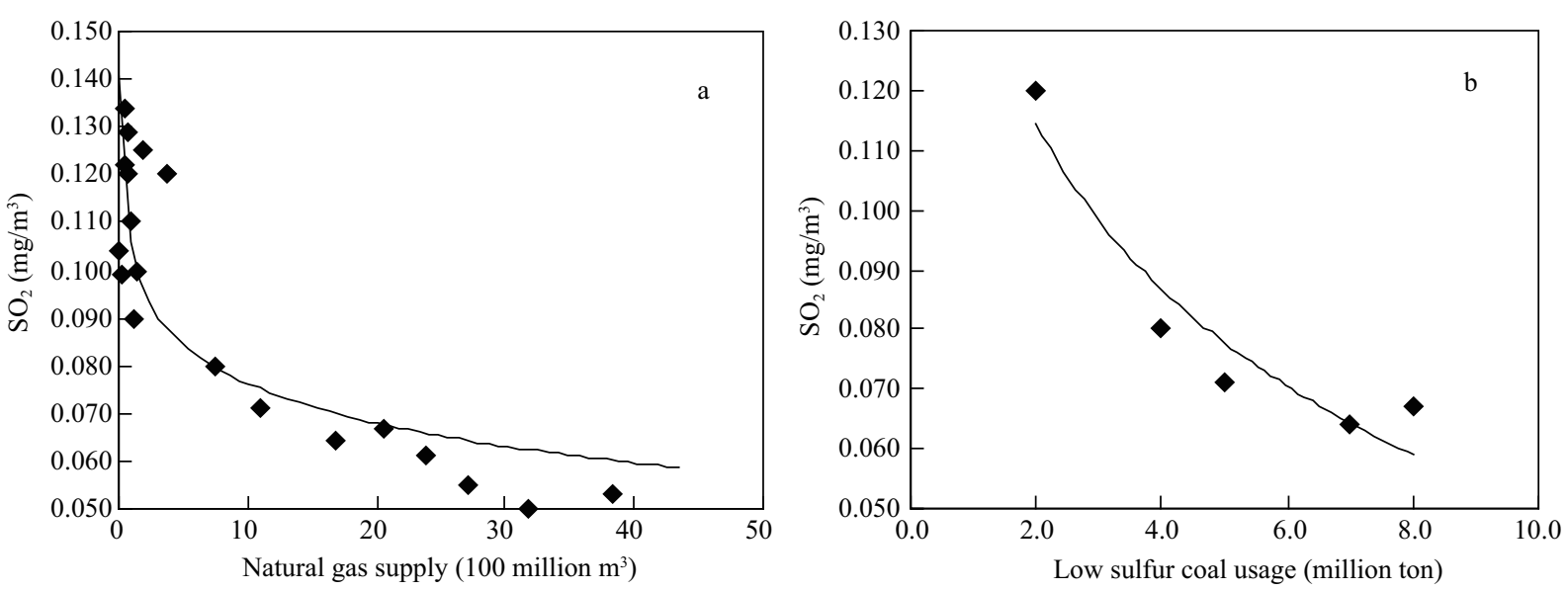

Fig. 7 Relationship between natural gas supply and $\mathrm{SO}_{2}$ (a) and between low-sulfur coal usage and $\mathrm{SO}_{2}(\mathrm{~b})$.

generation structure in such a short time. Therefore, the use of clean coal has also been implemented. A standard for low sulfur coal and its products was published by the government of Beijing in 1998, and the sulfur content of coal for heating was restricted to less than $0.5 \%$. This measure alone has the potential to reduce the $\mathrm{SO}_{2}$ pollution by about half, as the coal, which was available in the north of China, had an average sulfur content of $0.92 \%$. The reduction in the $\mathrm{SO}_{2}$ concentration was also significantly correlated with the increased use of low sulfur coal in recent years ( $p<0.05$, Fig. $7 b$ ). The use of clean coal is helpful for improving air quality.

Improved energy efficiency also influenced the air quality. The average energy consumption per thousand CNY of GDP was 1.05 tons of SCE in 1983 (Fig. 8). If this level of energy efficiency had not changed, the total energy consumption in 2007 would have been 982 million tons of SCE in 2007, which was 15.6 times the actual consumption. In fact, the average energy consumption per thousand CNY of GDP in 2007 was 0.07 tons of SCE, about $6 \%$ that of 1983 . The average energy consumption by industry was reduced by almost $90 \%$ in 2007 compared with 1983. Improved energy efficiency to reduce the energy consumption which may cause pollution was also a positive factor in improving air quality.

In a word, energy use is an important factor in air quality of Beijing.

\subsubsection{Industrial pollution sources}

Emissions from industrial pollution sources could lead to worse air quality. About $50 \%$ of the main industrial pollution sources, including electricity generation plants and chemical plants, were located in the suburban area of Beijing at one time. These factories had very large emissions of soot and powder that caused high levels of TSP and dustfall pollution which were $3 \%$ to $10 \%$ higher in the suburbs than in the urban area. These pollution sources were asked to gradually move out of the suburbs, or required to use proper technologies and methods to control the pollution, which is one of the series of protective measures implemented in Beijing. Based on incomplete statistics, more than 300 factories have been moved out and more than 1700 improvement projects have been finished in the past 25 years. More than $90 \%$ of sulfur and $95 \%$ of dust in the exhaust gas could be reduced by boiler desulfurization technologies. Comparing the situation in 2007 to that in 1986, the emissions of $\mathrm{SO}_{2}$ and soot in Beijing have been cut by $54 \%$ and $88 \%$ respectively, which equates to a reduction from 323,000 tons and 395,000 tons in 1986 to 152,000 tons and 19,000 tons in 2007. The industrial discharge volumes of $\mathrm{SO}_{2}$, industrial smoke and dust, and industrial powder dust have declined from

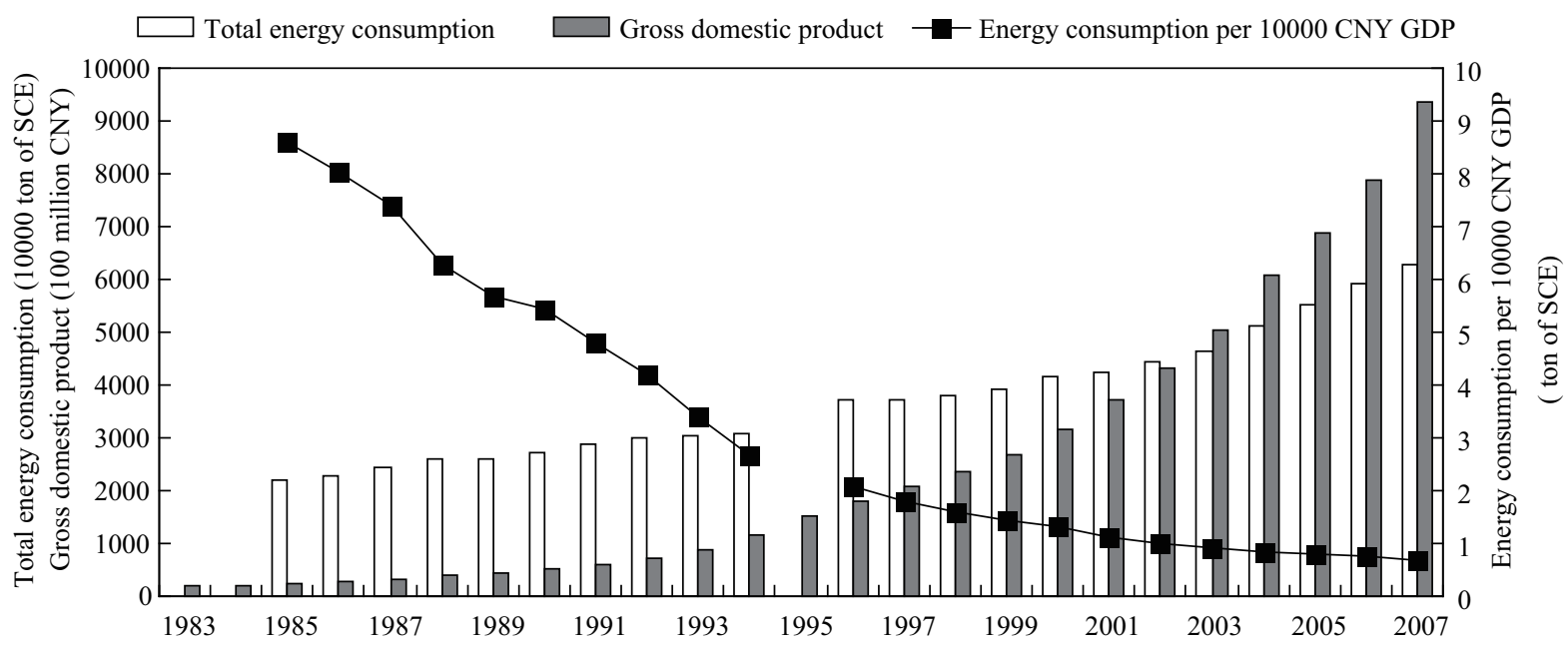

Fig. 8 Total energy consumption and energy consumption per 10000 CNY GDP. 


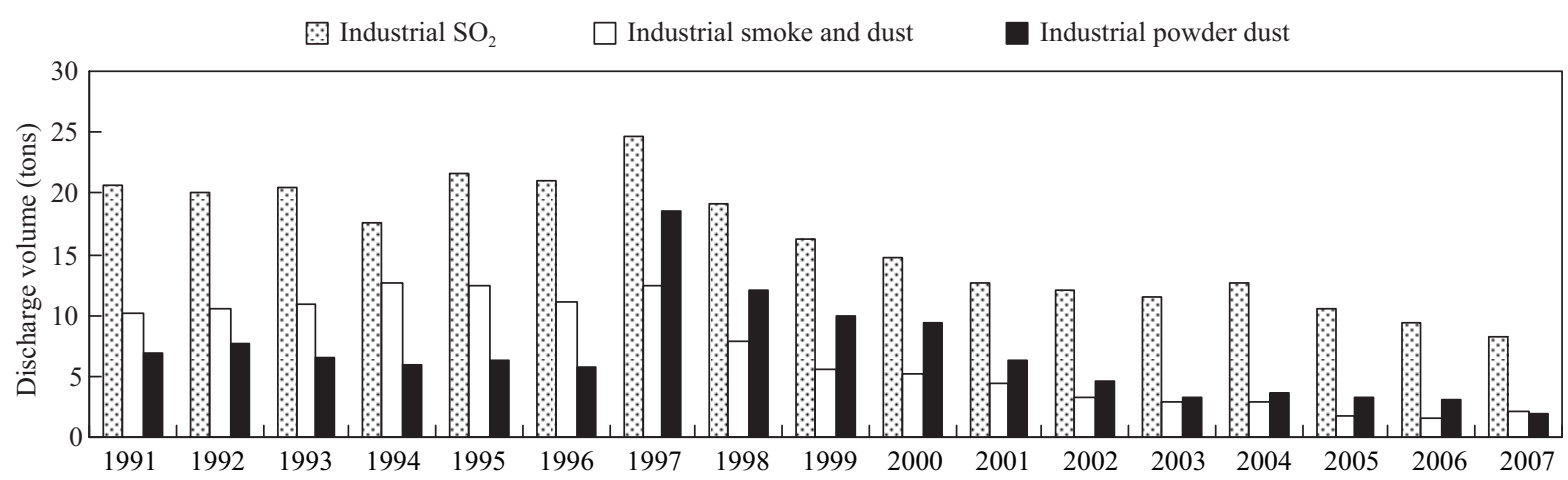

Fig. 9 Discharge volume changes in industrial $\mathrm{SO}_{2}$, industrial smoke and dust and industrial powder dust.

$206,000,101,000$ and 69,000 tons in 1991 to 83,000 , 21,000 and 19,000 tons in 2007 respectively (Fig. 9). The control of industrial pollution sources helped to protect the air quality in Beijing.

\subsubsection{Vehicle exhaust}

Vehicle exhaust could have impact on the pollution of NOx. According to information from the United Nations Environment Programme, over 90\% of urban air pollution in major cities, especially in developing countries, is attributed to vehicle emissions (www.unep.org/urban_environment/Issues/urban_air.asp). The quantity of motor vehicles in Beijing increased from 0.14 million in 1983 to more than 3.07 million in 2007, an annual growth of approximately 14\%. And the concentration of NO $x$ rose from $0.069 \mathrm{mg} / \mathrm{m}^{3}$ in 1983 to $0.152 \mathrm{mg} / \mathrm{m}^{3}$ in 1998 . The rapid increase in vehicles is significantly correlated with the increase in NOx concentration (Fig. 10, $p<0.01$ ). This large increase in pollution sources was the main reason for the degradation of the air quality related to NOx.

Meanwhile strict standards were implemented to reduce pollution and lighten the environmental pressure caused by increased pollution sources. Beijing implemented the national I standard in 1999, followed by the national II standard in 2002, the national III standard in 2005 and the national IV standard in 2008, which was always ahead of the national schedule by about two years. These standards and limits are useful for vehicle pollution emission control. For example, the emission standard for exhaust pollutants from light duty vehicles published in Beijing, 1999, which is equal to the European standard published in early 1990 's, could reduce $80 \%$ of NO $x$ exhaust from new light duty vehicles. Comparing 1998 and 2004 (before and after implementation of the standard), the NOx concentration had dropped by $22 \%$ over the six year period although the quantity of motor vehicles in Beijing increased from 1.16 to 2.17 million at the same time. After 1998 the relationship between the increase in vehicle numbers and NO $x$ concentration was not as well correlated as before 1998 (Fig. 10). This correlation coefficient was 0.915 before 1998 ( $p<0.01)$. It changed to -0.678 after 1998 with no significance $(p>0.05)$. It seemed that the increase in pollution sources enhanced the environmental pressure while implementation of strict standards reduced it, which causes the variation of the air quality related to NOx.

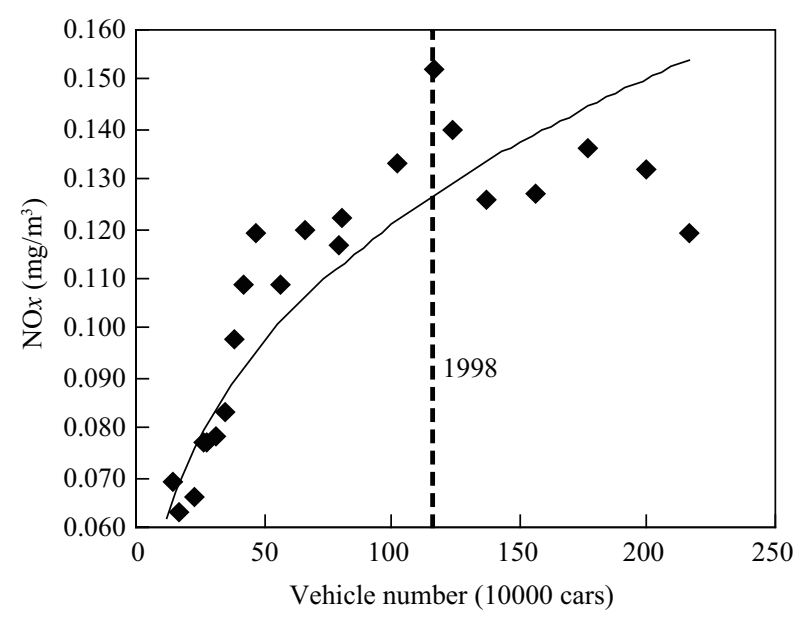

Fig. 10 Relationship between vehicle numbers and NO $x$ concentration from 1981 to 2004 .

\section{Discussion}

\subsection{Summarization of trend patterns}

The results for pollutant concentrations show that different pollutants have different patterns, which can be summarized into three general trends, a decreasing trend, an increasing trend and a flat trend. The decreasing trend can be divided into two sub-trends. One is a generally decreasing sub-trend, which occurs with $\mathrm{SO}_{2}$. Although $\mathrm{SO}_{2}$ had fluctuating increases before 1998, its concentration then declined significantly and had an overall downward tendency in the past 25 years. The other sub-trend was a continuously decreasing sub-trend, which occurred for dustfall and $\mathrm{B}[\mathrm{a}] \mathrm{P} . \mathrm{NO}_{2}$ and $\mathrm{PM}_{10}$, the substitute indicators for NO $x$ and PM since 1998, as also fitted this sub-trend. NO $x$ fitted the increasing trend, and had a significant upward tendency over the past two decades, with the concentration only reducing slightly after 1998. The flat trend also could be divided into two sub-trends. One sub-trend showed an increasing tendency at first, with concentrations later decreasing, so no overall trend could be identified. The annual variations of $\mathrm{CO}$ and ozone pollution fitted this sub-trend. The other sub-trend showed an almost continuously flat trend, and this was observed for TSP and $\mathrm{Pb}$.

\subsection{Change in the general characteristics of air pollu- tion}

Variations in the ratio of pollutants usually showed a 
change in the general characteristics of the air pollution. According to the result, the ratio of $\mathrm{NO} x$ to $\mathrm{SO}_{2}$ in 1984 and the ratio of $\mathrm{NO}_{2}$ to $\mathrm{SO}_{2}$ in 1998 were comparatively low, which showed the significant impact of $\mathrm{SO}_{2}$ at that time. The $\mathrm{SO}_{2}$ pollution was mainly caused by coal burning. It seemed that the air pollution pattern in Beijing at that time was coal burning problems. During the past two decades, the concentration of $\mathrm{SO}_{2}$ has declined and the concentration of NOx increased. Although the concentration of $\mathrm{NO}_{2}$ has declined in the recent years, the ratio of $\mathrm{NO}_{2}$ to $\mathrm{SO}_{2}$ rose continuously. The increasing difference shows the increased impact of nitrogen oxides. The ratio of TSP to $\mathrm{SO}_{2}$ and $\mathrm{PM}_{10}$ to $\mathrm{SO}_{2}$ also increased, reflecting the increasing impact of particulate matter. Nitrogen oxides and particulate matter are the main pollutants of vehicle emission. It seems that pollution from vehicle exhausts gradually played an important role. On the other hand, although the $\mathrm{SO}_{2}$ concentration has declined continuously since 1998, it still often exceeds the air quality standard of China during the heating season. The negative impact of $\mathrm{SO}_{2}$ cannot be totally ignored. To sum up, the study has revealed that the air pollution pattern in Beijing has changed from coal burning being the major cause of problems to a mixture of pollutant sources mainly dominated by vehicle exhausts and coal burning.

\subsection{Interaction of anthropogenic driving factors}

Industrial structure, energy use, industrial pollution sources, and vehicle exhaust all have important impact on air quality. Partial correlation analysis was applied to analyze which was the main factor of different pollutants (Table 1). The concentration of $\mathrm{SO}_{2}$ was related to the change in industrial structure, coal use, industrial discharges and motor vehicle emissions. However, industrial $\mathrm{SO}_{2}$ discharges had the most significant positive correlation with the concentration of $\mathrm{SO}_{2}$ when the impacts of other factors were removed. Similarly when the impacts of other factors were removed, the increase in the proportion of GDP contributed by tertiary industry was a significant factor to NOx. The change in industrial structure and the energy use were the main driving factors affecting $\mathrm{CO}$ concentrations. However, it is quite difficult to quantify the air control policies, some misunderstanding appeared. The variation in NOx was negative correlated with the use of gasoline, kerosene and diesel fuel oil, which seemed unreasonable, but could be interpreted by strict control policies on NOx pollution, resulted in the declining of NO $x$ concentration while the proportion of oil in final consumption increased. As there was a lack of appropriate method to quantify the air quality control policies, further study on how to take into account of policies was greatly needed.

\subsection{Impact of protective measures}

The rapid development in Beijing has resulted in serious air pollution problems. From 1983 to 1998, the concentrations of pollutants increased overall, and the air quality deteriorated. The gray sky gradually caught the attention of both the government and the public. Great efforts have been made to improve the air quality, particularly since 1998. A series of protective measures have been implemented, including pollution control on coal combustion, motor vehicle emissions, industrial emissions and construction and road dust. Strict air quality standards and limits were published. Up to the present, fifteen stages of air pollution control measures including more than 200 details have been implemented to improve the air quality. For example, more than 16,000 coal fired boilers which are less than 20 steam tons have been reformed since 1998 to control the coal combustion pollution. The natural gas supply has increased from 0.38 billion cubic meters in 1983 to 4.34 billion cubic meters in 2007 to reduce the coal consumption. And the $\mathrm{SO}_{2}$ emission during 1998 to 2007 was $60 \%$ of that during 1983 to 1998 . The national I standard to national IV standard were implemented since 1999 to control motor vehicle emissions. Old cars were asked to get out of use. The emissions from vehicles complying with the IV standard of China are less than $4 \%$ of emissions from vehicles before 1998 when there was no corresponding standard. From 1998 to 2007 most of the pollutants have had downward tendencies. Although the economy, population, energy consumption and number of vehicles in Beijing have increased rapidly, the air quality is better than might be expected based on to the trends prior to 1998 . The air protection policies have great success in improving the ambient air quality in Beijing.

\subsection{Other factors affecting air quality}

As discussed before, industrial structure, energy use, industrial pollution sources, and vehicle exhaust were the main driving factors affecting the air quality, and protective measures had significant impact on the air quality. However, there were still other factors, such as natural conditions, city constructing activities, the interaction between natural and anthropogenic influence. As the air pollution pattern in Beijing has changed to a mixture problem, particulate matter (PM) and ozone pollution had caught attention.

$\mathrm{PM}$ is the dominant pollutant in Beijing at present.

Table 1 Partial correlation analysis between pollutants and their main driving factors

\begin{tabular}{llllll}
\hline & $\begin{array}{l}\text { Proportion of tertiary } \\
\text { industry in GDP }\end{array}$ & $\begin{array}{l}\text { Proportion of coal } \\
\text { in final consumption }\end{array}$ & $\begin{array}{l}\text { Proportion of oil } \\
\text { in final consumption }\end{array}$ & $\begin{array}{l}\text { Industrial } \mathrm{SO}_{2} \\
\text { discharge }\end{array}$ & $\begin{array}{l}\text { Industrial dust } \\
\text { discharge }\end{array}$ \\
\hline $\mathrm{SO}_{2}$ & 0.295 & 0.522 & - & $0.842^{\mathrm{a}}$ & - \\
$\mathrm{NO} x$ & $0.566^{\mathrm{b}}$ & - & $-0.696^{\mathrm{a}}$ & - & - \\
$\mathrm{CO}$ & $0.746^{\mathrm{b}}$ & $0.734^{\mathrm{b}}$ & $-0.662^{\mathrm{b}}$ & 0.216 & 0.385 \\
$\mathrm{TSP}$ & 0.391 & -0.172 & 0.506 & -0.400 & 0.167 \\
\hline
\end{tabular}

${ }^{\mathrm{a}}$ Correlation is significant at the 0.01 level (2-tailed); ${ }^{\mathrm{b}}$ correlation is significant at the 0.05 level (2-tailed). 
The main sources of PM include coal combustion, motor vehicle emissions, industrial emissions, construction dust, road dust, biomass burning and secondary pollution (Bi et al., 2007; Kim and Hopke, 2008; Shi et al., 2007). PM is affected by both anthropogenic and natural conditions (DeGaetano and Doherty, 2004; Han et al., 2008; Wang et al., 2004). About 7\%-20\% of the PM came from natural sources such as soil dust in Beijing (Song et al., 2007; Wang et al., 2008b). Higher precipitation levels in summer are helpful for cleaning the air and the concentration of $\mathrm{PM}$ in summer is $20 \%-30 \%$ lower than the annual average. However, natural conditions during winter and spring can adversely affect pollution levels. For example, half of the time during the heating season Beijing has stable meteorological conditions which reduce diffusion, potentially causing higher concentrations of pollutants. Dust storms often appear during spring while the vegetation coverage is reduced causing dusty days in Beijing. Due to these factors, the concentration of PM is $10 \%-30 \%$ higher than the annual average during the winter and spring period. Considering the impact of dust storms in 2000-2002, the annual average PM concentration would reduce by 0.015 $\mathrm{mg} / \mathrm{m}^{3}$ if dust storms did not affect the city. The interaction of natural conditions and anthropogenic pollution leads to complex variations in PM concentrations which showed no significance trend. For instance, the highest precipitation levels within the past twenty years was recorded in 1994. However, the third ring road was under construction that year. Along with the impact of dust storms in spring, the annual average concentration of TSP was $0.395 \mathrm{mg} / \mathrm{m}^{3}$ in 1994, which was the highest in the past two decades. Further study is needed on the natural and anthropogenic impact and the local and regional impact.

Ozone pollution has also become a problem lately. Ozone is usually formed from a photochemical reaction, which requires suitable meteorological conditions including high temperature, low relative humidity, abundant sunshine and low wind speed (Aneja et al., 2000). This kind of pollution was once considered to be much like a natural process. However, recent research has identified that compounds in vehicle exhausts such as NOx, CO and hydrocarbons are considered to be the precursors of ozone (Sillman, 1999). $\mathrm{O}_{3}$ is formed photochemically from the photolysis of $\mathrm{NO}_{2}$. And $\mathrm{NO}_{2}$, one kind of $\mathrm{NO} x$, could be considered to have high correlation with the anthropogenic source of vehicles. Volatile organic compounds (VOCs) also influence the formation of ozone (Lin et al., 2005; Stein et al., 2005). The degradation reactions of VOCs lead to the formation of intermediate which react with $\mathrm{NO}$, converting $\mathrm{NO}$ to $\mathrm{NO}_{2} . \mathrm{NO}_{2}$ is then photolyzed to form $\mathrm{O}_{3}$. These contaminants are generally attributed to anthropogenic activities and have increased the ozone pollution.

\section{Conclusions}

In this study, the variation in the ambient air quality in Beijing since the 1980's was analyzed using the Daniel trend test based on the data from long-term monitoring stations. The results showed that different pollutants displayed three trends: a decreasing trend, an increasing trend and a flat trend. The general air pollution pattern in Beijing had changed from problems caused by coal burning to mixed traffic exhaust and coal-related pollution. Industrial structure, energy use, industrial pollution sources, and vehicle exhaust all have important impact on air quality. The interaction between pollution sources change and implementation of air pollution control measures was the main driving factor that caused the variation in air quality.

\section{Acknowledgments}

This work was supported by the State Key Program of National Natural Science Foundation of China (No. 41030744) and the Specialized Research Fund of State Key Laboratory of Urban and Regional Ecology.

\section{References}

Aneja P V, Adams A A, Arya S P, 2000. An observational based analysis of ozone trends and production for urban areas in North Carolina. Chemosphere-Global Change Science, 2(2): 157-165.

Baldasano M J, Valera E, Jiménez P, 2003. Air quality data from large cities. Science of the Total Environment, 307(1-3): 141-165.

Beijing Municipal Statistical Bureau, 1983-2007. Beijing Statistical Yearbook. China Statistics Press, Beijing.

Bi X H, Feng Y C, Wu J H, Wang Y Q, Zhu T, 2007. Source apportionment of $\mathrm{PM}_{10}$ in six cities of northern China. Atmospheric Environment, 41(5): 903-912.

DeGaetano A T, Doherty O M, 2004. Temporal, spatial and meteorological variations in hourly $\mathrm{PM}_{2.5}$ concentration extremes in New York City. Atmospheric Environment, 38(11): 1547-1558.

Fenger J, 2009. Air pollution in the last 50 years-From local to global. Atmospheric Environment, 43(1): 13-22.

Gupta I, Kumar R, 2006. Trends of particulate matter in four cities in India. Atmospheric Environment, 40(14): 25522566.

Han Y X, Fang X M, Zhao T L, Kang S C, 2008. Long range trans-Pacific transport and deposition of Asian dust aerosols. Journal of Environmental Sciences, 20(4): 424428.

Hyslop N P, 2009. Impaired visibility: the air pollution people see. Atmospheric Environment, 43(1): 182-195.

Kahn M E, 1997. Particulate pollution trends in the United States. Regional Science and Urban Economics, 27(1): 87-107.

Kim E, Hopke P K, 2008. Source characterization of ambient fine particles at multiple sites in the Seattle area. Atmospheric Environment, 42(24): 6047-6056.

Lin C J, Ho T C, Chu H W, Yang H, Chandru S, Krishnarajanagar $\mathrm{N}$ et al., 2005. Sensitivity analysis of ground-level ozone concentration to emission changes in two urban regions of southeast Texas. Journal of Environmental Management, 75(4): 315-323.

Lin C Y C, Jacob D J, Fiore A M, 2001. Trends in exceedances of the ozone air quality standard in the continental United States, 1980-1998. Atmospheric Environment, 35(19): 3217-3228.

Maddison A, 2003. The World Economy: a Millennial Perspec- 
tive. Peking University Press, Beijing.

Mayer H, 1999. Air pollution in cities. Atmospheric Environment, 33(24-25): 4029-4037.

Mukerjee S, 2001. Selected air quality trends and recent air pollution investigations in the US-Mexico border region. Science of the Total Environment, 276(1-3): 1-18.

Qu G P, 2002. The Complete Volume of Chinese Environmental Protection Work. China Environmental Science Press, Beijing.

Qu G P, 1998. Adjust industry and energy structure to solve air pollution in Beijing. Energy Policy Research, (1): 10-13.

Shi Z B, He K B, Yu X C, Yao Z L, Yang F M, Ma Y L et al., 2007. Diurnal variation of number concentration and size distribution of ultrafine particles in the urban atmosphere of Beijing in winter. Journal of Environmental Sciences, 19(8): 933-938.

Sillman S, 1999. The relation between ozone, NO $x$ and hydrocarbons in urban and polluted rural environments. Atmospheric Environment, 33(12): 1821-1845.

Song Y, Tang X Y, Xie S D, Zhang Y H, Wei Y J, Zhang M S et al., 2007. Source apportionment of $\mathrm{PM}_{2.5}$ in Beijing in 2004. Journal of Hazardous Materials, 146(1-2): 124-130.

Stein A F, Mantilla E, Millán M M, 2005. Using measured and modeled indicators to assess ozone-NO $x$-VOC sensitivity in a western Mediterranean coastal environment. Atmospheric
Environment, 39(37): 7167-7180.

Wang H L, Zhuang Y H, Wang Y, Sun Y L, Yuan H, Zhuang $\mathrm{G} \mathrm{S}$ et al., 2008b. Long-term monitoring and source apportionment of $\mathrm{PM}_{2.5} / \mathrm{PM}_{10}$ in Beijing, China. Journal of Environmental Sciences, 20(11): 1323-1327.

Wang J L, Zhang Y H, Shao M, Liu X L, Zeng L M, Cheng $\mathrm{C}$ L et al., 2004. Chemical composition and quantitative relationship between meteorological condition and fine particles in Beijing. Journal of Environmental Sciences, 16(5): 860-864.

Wang Q X, Liu Y, Pan X C, 2008a. Atmosphere pollutants and mortality rate of respiratory diseases in Beijing. Science of the Total Environment, 391(1): 143-148.

Weatherley N S, Timmis R J, 2001. The atmosphere in England and Wales: an environmental management review. Atmospheric Environment, 35(32): 5567-5580.

Wise E K, Comrie A C, 2005. Meteorologically adjusted urban air quality trends in the Southwestern United States. Atmospheric Environment, 39(16): 2969-2980.

World Bank, 2007. World Development Indicators. http:// siteresources.worldbank.org/DATASTATISTICS/Resources/ table3_13.pdf

Zhou K, Ye Y H, Liu Q, Liu A J, Peng S L, 2007. Evaluation of ambient air quality in Guangzhou, China. Journal of Environmental Sciences, 19(4): 432-437. 